\title{
Análise de componentes principais da variação de peso da vaca durante a gestação na programação fetal de fêmeas
}

\author{
Analysis of main components of cow weight variation during pregnancy in fetal programming of \\ females \\ Análisis de los componentes principales de la variación del peso de la vaca durante la gestación en \\ la programación fetal de las hembras
}

\section{Resumo}

Objetivou-se avaliar o impacto da variação de peso da vaca durante a gestação no desenvolvimento e nas características produtivas da carcaça e da carne de novilhas abatidas aos 18 meses de idade. Foram utilizadas 35 vacas e sua progenie. Os tratamentos avaliados foram determinados de acordo com a variação de peso da matriz durante a gestação, expresso em porcentagem do peso vivo da matriz no final do período de reprodução. Os tratamentos foram: G10, vacas que ganharam de 0,1 a $10,0 \%$ do peso vivo durante a gestação; P10, vacas que perderam de 0,1 a $10,0 \%$ do peso vivo durante a gestação; P20, vacas que perderam de 10,1 a 20,0 \% do peso vivo durante a gestação. Os dados foram analisados estatisticamente através de análise multivariada e da técnica de componentes principais. As variáveis PNAS, PAJDESM, PAJ365, PAJ420, PAJ540, GMD, RCQ, RCF, AOL, GORD, ICC, DIAN, COST, CON, MAT e EGS não foram influenciadas pelo desempenho materno durante a gestação. Já o PCQ, PCF, MUSC, OSSO, TRAS e MARM apresentaram correlação significativa com dois componentes principais. $O$ tratamento G10 apresentou maiores valores para PCQ, PCF, TRAS, MUSC e MARM, ficando localizadas no quadrante I. O tratamento P10 apresentou maior quantidade de OSSO na carcaça, no quadrante IV. Já o tratamento P20 ficou localizado no quadrante II, apresentando os piores valores para as referidas variáveis. A variação de peso da vaca durante a gestação não influencia no desenvolvimento da progênie, porém impacta nas características de carcaça e carne.

Palavras-chave: Carcaça; Gestação; Multivariada; Novilha. 


\begin{abstract}
The objective of this study was to evaluate the impact of cow's weight variation during gestation on the development and productive characteristics of the carcass and the meat of heifers slaughtered at 18 months of age. Thirty - five cows and their progeny were used. The evaluated treatments were determined according to the matrix weight variation during gestation, expressed as a percentage of the live weight of the matrix at the end of the breeding period. Treatments were: G10, cows that gained from 0.1 to $10.0 \%$ of live weight during gestation; P10, cows that lost 0.1 to $10.0 \%$ of live weight during gestation; P20, cows that lost from 10.1 to $20.0 \%$ of live weight during gestation. Data were analyzed statistically through multivariate analysis and the main components technique. The variables PNAS, PAJDESM, PAJ365, PAJ420, PAJ540, GMD, RCQ, RCF, AOL, GORD, ICC, DIAN, COST, CON, MAT and EGS of heifers were not influenced by maternal performance during gestation. The PCQ, PCF, MUSC, OSSO, TRAS and MARM presented significant correlation with two main components. The G10 treatment presented higher values for PCQ, PCF, TRAS, MUSC and MARM, being located in the I quadrant. Treatment P10 presented a greater amount of OSSO in the carcass, in the IV quadrant. On the other hand, the P20 treatment was located in the II quadrant, presenting the worst values for these variables. The variation in the weight of the cow during pregnancy does not influence the development of the progeny, but it does impact the carcass and meat characteristics.
\end{abstract}

Keywords: Carcass; Heifer; Multivariate; Pregnancy.

\title{
Resumen
}

El objetivo de este estúdio fue evaluar el impacto de la variación del peso de las vacas durante la gestación en el desarrollo y las características productivas de la canal y carne de novillas sacrificadas a los 18 meses de edad. Se utilizaron 35 vacas y su progenie. Los tratamientos evaluados se determinaron de acuerdo con la variación de peso de la matriz durante la gestación, expresada como porcentaje del peso vivo de la matriz al final del período reproductivo. Los tratamientos fueron: G10, vacas que ganaron 0,1 a 10,0\% del peso vivo durante la gestación; P10, vacas que perdieron de 0.1 a $10.0 \%$ del peso vivo durante la gestación; P20, vacas que perdieron del 10,1 al 20,0\% del peso vivo durante la gestación. Los datos se analizaron estadísticamente mediante análisis multivariado y la técnica de componentes principales. Las variables PNAS, PAJDESM, PAJ365, PAJ420, PAJ540, GMD, RCQ, RCF, AOL, GORD, ICC, DIAN, COST, CON, MAT y EGS no fueron influenciadas por el desempeño materno. El PCQ, PCF, MUSC, OSSO, TRAS y MARM presentaron una correlación significativa con dos componentes principales. El tratamiento G10 mostró valores más altos para PCQ, PCF, TRAS, MUSC y MARM, ubicándose en el cuadrante I. El tratamiento P10 mostró una mayor cantidad de HUESO en la canal, en el cuadrante IV. El tratamiento P20 se ubicó en el cuadrante II, presentando los peores valores para las variables referidas. La variación en el peso de la vaca durante la gestación no influye en el desarrollo de la progenie, pero sí afecta las características de la canal y la carne.

Palabras clave: Canal; Gestación; Multivariante; Novilla.

\section{Introdução}

A programação fetal é um período específico durante a gestação no qual o desenvolvimento fetal é afetado por diversos fatores, entre eles nutricionais, que alteram a trajetória de desenvolvimento e produtiva, resultando em efeitos persistentes na vida do animal (Du et al., 2010).

Estudos apontam impactos da programação fetal no desenvolvimento e nos índices produtivos da progênie (Larson et al., 2009; Underwood et al., 2010; Underwood et al., 2008; Tong et al., 2008; Funston et al., 2010). Um baixo plano nutricional durante a gestação afeta negativamente as variáveis peso ao nascer (Greenwood et al., 2010; Du et al., 2010), miogênese, número de fibras musculares, massa muscular, marmoreio e a adipogênese na progênie (Tong et al., 2008; Underwood et al., 2008; Greenwood e Cafe, 2007; Du et al., 2010).

Os rebanhos de cria são corriqueiramente destinados em áreas de solo de menor fertilidade e com alta carga animal superando a capacidade de suporte da pastagem natural (Pellegrini e Lopes, 2011). As pastagens naturais do Bioma Pampa são caracterizadas por alta qualidade nutricional na primavera e no verão e baixa qualidade nutricional no outono e inverno (Pereira et al., 2018) o qual coincide com o período gestacional dos rebanhos de cria no Rio Grande do Sul. A nutrição inadequada das vacas prenhas pode ser causada por efeitos das condições climáticas ou por declínio da qualidade ou quantidade de forragem disponível, impactando no peso das vacas durante a gestação.

Existem poucos trabalhos na literatura que abordem os efeitos da programação fetal nas características de carcaça e carne de fêmeas, a maioria dos estudos publicados no referido tema, exploram os impactos nas carcaças de machos. Já os estudos com fêmeas estão majoritariamente ligados ao desempenho reprodutivo. Porém com a intensificação dos sistemas 
produtivos de bezerros, taxas de desmame superiores a 80\%, acarretam em elevação na produção de fêmeas para terminação em idade jovem, em função da redução na taxa de reposição de matrizes. Esse fato eleva a participação de fêmeas de descarte na taxa de desfrute das propriedades e de abate nos frigoríficos (Vaz et al., 2010). No Brasil são abatidos anualmente cerca de 42 milhões de cabeças de bovinos, das quais $48,8 \%$ do total são fêmeas, índice esse que vem se mantendo constante nos últimos dez anos (Anualpec, 2016).

De acordo com o exposto acima, justifica-se o estudo do impacto da variação de peso da vaca durante a gestação no desenvolvimento e nas características produtivas da carcaça e da carne de novilhas abatidas aos 18 meses de idade.

\section{Metodologia}

O protocolo experimental utilizado na fase de terminação e abate dos animais foi aprovado pela Comissão de Ética no Uso de Animais da Universidade Federal de Santa Maria (UFSM), aprovado sob o parecer n 128/2014.

\section{Animais e fatores de estudo}

O experimento foi realizado na Universidade Federal de Santa Maria, localizada na depressão central do Rio Grande do Sul. O clima da região é do tipo Cfa (subtropical úmido) conforme classificação de Köppen (Alvares et al., 2013). O solo da área experimental pertence à unidade de mapeamento São Pedro e é classificado como Argissolo Vermelho distrófico arênico (Streck et al., 2008).

Foram utilizadas 35 vacas de corte e sua progênie, com composição multirracial Charolês x Nelore, todos oriundos do mesmo rebanho experimental. As vacas foram submetidas a período reprodutivo compreendido entre os meses de dezembro de 2011 a fevereiro de 2012, sendo composto por 45 dias de inseminação artificial e 45 dias de repasse na proporção de 4\% de touros. Durante o referido período as vacas foram mantidas em pastagem natural com taxa de lotação média de $333 \mathrm{~kg} \mathrm{ha}^{-1} \mathrm{de}^{\mathrm{d}}$ peso vivo, o que representa 0,74 unidade animal por hectare, estando dentro do recomendado de manejo para pastagens naturais no Bioma Pampa, $350 \mathrm{~kg} \mathrm{ha}^{-1}$ de peso vivo (Nabinger et al., 2009). Ao final do período de reprodução foi coletado o peso final de monta das vacas (PFM), através da utilização de balança eletrônica digital.

A parição ocorreu nos meses de setembro a novembro de 2012. Após o parto vaca e bezerro foram conduzidos ao centro de manejo, para realização da pesagem e identificação do bezerro e pesagem e avaliação do escore de condição corporal da matriz, seguindo escala proposta por Ferreira et al. (2013).

Os tratamentos avaliados foram determinados de acordo com a variação de peso da matriz durante a gestação, expresso em porcentagem do peso vivo da matriz no final do período de reprodução. Dessa forma, os tratamentos foram: G10 $(n=9)$, vacas que ganharam de 0,1 a 10,0 \% do peso vivo durante a gestação; P10 (n=16), vacas que perderam de 0,1 a $10,0 \%$ do peso vivo durante a gestação; P20 (n=10), vacas que perderam de 10,1 a 20,0 \% do peso vivo durante a gestação.

As bezerras foram submetidas ao desmame precoce com idade média de 75 dias e recriadas, em pastagem de Tifton 85 (Cynodon spp.), recebendo a quantidade de $1 \%$ do peso corporal de ração com $18 \%$ de proteína bruta (PB). Durante o inverno os bezerros foram recriados em pastagem cultivada de aveia (Avena strigosa) e azevém (Lolium multiflorum), manejado com taxa de lotação média de $800 \mathrm{~kg} \mathrm{ha}^{-1}$ de peso vivo. Após o período de recria, quando apresentavam em média 15 meses de idade, os animais foram terminados em pastagem de sorgo forrageiro (Sorghum bicolor), com carga animal média de $1200 \mathrm{~kg} \mathrm{ha}^{-1}$ de peso vivo, recebendo suplementação à nível de $1 \%$ do peso corporal. Os níveis de PB e nutrientes digestíveis totais (NDT) do suplemento foram de $144,0 \mathrm{~g} \mathrm{Kg}^{-1}$ de MS e $767,0 \mathrm{~g} \mathrm{Kg}^{-1}$ de MS respectivamente, baseados nas exigências nutricionais dos animais. Todos os tratamentos receberam o mesmo suplemento, que foi formulado a partir da relação de $62,9 \%$ de grão de aveia branca, $35 \%$ de grão de milho, $1 \%$ de uréia e $1,1 \%$ de calcário calcítico. O sorgo forrageiro 
apresentou em média 164,14 $\mathrm{g} \mathrm{Kg}^{-1}$ de MS de PB e 707,64 $\mathrm{g} \mathrm{Kg}^{-1}$ de MS de NDT. Em todas as fases os animais foram manejados coletivamente.

\section{Medidas de desempenho}

O desenvolvimento dos animais foi medido através das pesagens realizadas ao nascer (PNAS), ao desmame precoce (PAJDESM), aos 210 dias de idade (PAJ210), aos 365 dias (PAJ365), no início do período de terminação (PAJ420) e ao final do período de terminação (PAJ540). Todos os pesos obtidos nas referidas pesagens foram ajustados através da fórmula: $P a j=\left(P 2-P 1 / N^{\circ}\right.$ dias $) \times N^{\circ}$ dias $+P 1$, Onde: $\mathrm{P} 1=$ peso do animal na primeira pesagem; $\mathrm{P} 2=$ peso do animal na segunda pesagem; $\mathrm{N}^{\circ}$ dias= número de dias entre as pesagens, com o objetivo de retirar o efeito da ordem de nascimento. $\mathrm{O}$ ganho de peso na terminação (GMD) foi obtido através da diferença entre o PAJ420 e PAJ540 dividindo pelo número de dias da referida fase (84 dias).

O critério de abate foi determinado pela espessura de gordura subcutânea mínima, na região do músculo Longissimus dorsi mínima de $3 \mathrm{~mm}$, especificamente sobre a $12^{\circ}$ e $13^{\circ}$ costela, com a captação de imagens através do ultrassom ALOKA SSD 500 e a interpretação das mesmas pelo programa BIOTRONIC - BioSoft Toolbox®.

Os animais foram abatidos, em frigorífico comercial, obedecendo ao fluxo normal do estabelecimento após jejum de sólidos e líquidos. Após o abate e antes da entrada das carcaças na câmera de resfriamento, foi obtido o peso de carcaça quente das carcaças. Após o resfriamento as carcaças foram novamente pesadas e, sendo obtido o rendimento de carcaça quente e fria em \% do peso corporal, a obtenção dos rendimentos de carcaça foi através da divisão do peso de carcaça (quente ou fria) pelo peso vivo de abate e multiplicado por 100. Nas duas meias-carcaças resfriadas também foram avaliadas a maturidade fisiológica e conformação seguindo a metodologia descrita por Leão et al. (2013). Na meia-carcaça fria esquerda foram separados os cortes comerciais traseiro, dianteiro e costilhar e pesados individualmente para determinação das suas proporções em relação à meia-carcaça. Para determinar as porcentagens de músculo, gordura e osso, seguiu-se a metodologia descrita por Rezende et al. (2012), sendo extraída uma porção do músculo Longissimus dorsi entre a $10^{\circ}$ e a $12^{\circ}$ costela, para posterior separação física dos referidos tecidos.

Na Tabela 1 são apresentadas as características descritivas das variáveis de desenvolvimento e de carcaça utilizadas no presente estudo. 
Tabela 1. Análise estatística descritiva das variáveis de desenvolvimento e de carcaça da progênie de vacas com diferentes variações de peso durante a gestação.

\begin{tabular}{|c|c|c|c|c|c|c|}
\hline Variável & $\mathrm{n}$ & Média & Mínimo & Máximo & DP & $\mathrm{CV}$ \\
\hline PNAS & 35 & 35,63 & 25,00 & 48,50 & 4,63 & 12,98 \\
\hline PAJDESM & 35 & 117,62 & 92,38 & 175,58 & 16,73 & 14,22 \\
\hline PAJ210 & 35 & 150,44 & 110,30 & 184,10 & 19,97 & 13,28 \\
\hline PAJ365 & 35 & 237,49 & 194,23 & 294,54 & 28,48 & 11,99 \\
\hline PAJ420 & 35 & 238,66 & 177,50 & 306,50 & 35,43 & 14,84 \\
\hline PAJ540 & 35 & 336,84 & 264,50 & 432,50 & 39,74 & 11,80 \\
\hline GMD & 35 & 0,84 & 0,49 & 1,08 & 0,13 & 15,69 \\
\hline PCQ & 35 & 195,35 & 148,10 & 255,90 & 24,66 & 12,63 \\
\hline PCF & 35 & 191,06 & 144,50 & 191,06 & 24,40 & 12,77 \\
\hline RCQ & 35 & 55,96 & 51,78 & 60,32 & 1,85 & 3,31 \\
\hline $\mathrm{RCF}$ & 35 & 54,72 & 50,52 & 59,01 & 1,86 & 3,39 \\
\hline AOL & 35 & 42,82 & 35,80 & 51,30 & 3,84 & 8,97 \\
\hline MARM & 35 & 3,97 & 2,00 & 8,00 & 1,59 & 40,27 \\
\hline MUSC & 35 & 121,19 & 83,89 & 152,67 & 15,67 & 12,93 \\
\hline GORD & 35 & 40,07 & 20,03 & 63,00 & 8,99 & 22,43 \\
\hline ICC & 35 & 1,63 & 1,30 & 2,11 & 0,17 & 10,82 \\
\hline OSSO & 35 & 31,26 & 24,87 & 38,43 & 3,35 & 10,72 \\
\hline TRAS & 35 & 108,92 & 85,00 & 138,80 & 13,25 & 12,17 \\
\hline DIAN & 35 & 71,28 & 53,60 & 93,20 & 9,67 & 13,57 \\
\hline COST & 35 & 21,16 & 15,40 & 29,40 & 3,24 & 15,33 \\
\hline $\mathrm{COM}$ & 35 & 8,57 & 6,00 & 11,00 & 1,06 & 12,42 \\
\hline MAT & 35 & 14,14 & 13,00 & 15,00 & 0,60 & 12,42 \\
\hline EGS & 35 & 3,54 & 2,00 & 6,67 & 1,12 & 31,69 \\
\hline
\end{tabular}

$\mathrm{n}=$ número de unidades amostrais; $\mathrm{DP}=$ desvio padrão; $\mathrm{CV}=$ coeficiente de variação; $\mathrm{PNAS}=\mathrm{kg} ; \mathrm{PAJDESM}=\mathrm{kg} ; \mathrm{PAJ} 210=\mathrm{kg} ; \mathrm{PAJ} 365=\mathrm{kg}$; $\mathrm{PAJ} 450=\mathrm{kg} ; \mathrm{PF}=\mathrm{kg} ; \mathrm{GMD}=\mathrm{kg} \mathrm{dia}{ }^{-1} ; \mathrm{PCQ}=\mathrm{kg} ; \mathrm{PCF}=\mathrm{kg} ; \mathrm{RCQ}=\% ; \mathrm{RCF}=\% ; \mathrm{AOL}=\mathrm{cm}^{2} ; \mathrm{MARM}=\operatorname{pontos} ; \mathrm{MUSC}=\mathrm{kg} ; \mathrm{GORD}=\mathrm{kg} ; \mathrm{ICC}=$ $\mathrm{kg} \mathrm{cm}^{-1} ; \mathrm{OSSO}=\mathrm{kg} ; \mathrm{TRAS}=\mathrm{kg} ; \mathrm{DIAN}=\mathrm{kg} ; \mathrm{COST}=\mathrm{kg} ; \mathrm{COM}=$ pontos$; \mathrm{MAT}=$ pontos$; \mathrm{EGS}=\mathrm{mm}$.

Fonte: Arquivo de dados do Laboratório de Bovinocultura de Corte da UFSM.

\section{Analises estatísticas}

As análises estatísticas foram realizadas da seguinte forma: primeiramente foi processada a análise multivariada com o propósito de verificar a existência de efeito significativo das classes de variação de peso da matriz durante a gestação no conjunto das variáveis de desenvolvimento e de carcaça e carne da progênie, após foi realizada análise de componentes principais (ACP).

O delineamento experimental foi o inteiramente casualizado, utilizando-se o modelo estatístico:

$$
\gamma_{i j k}=\mu_{k}+T_{j k}+O P+B_{i j k}
$$

onde: $y_{\mathrm{ijk}}$ é o valor observado da k-ésima variável, sob o i-ésimo grupo genético na j-ésima repetição; $\mu_{\mathrm{k}}$ é a média geral da k-ésima variável; $\mathrm{T}_{\mathrm{ik}}$ é o efeito do i-ésimo tratamento na k-ésima variável; OP é o efeito da covariável ordem de parição e eijk é o efeito aleatório associado à observação $y_{i j k}$, com i $=1,2, \ldots, 8 ; \mathrm{k}=1,2, \ldots ., 21 ; \mathrm{e} \mathrm{j}=1,2, \ldots ., \mathrm{r}(\mathrm{r}=$ número de repetições). Realizou-se teste de normalidade de Shapiro-Wilk em todas as variáveis, para verificar o comportamento normal dos resíduos 
Para testar a hipótese de que os vetores dos efeitos de tratamento eram nulos, foi utilizado o teste de Wilks (Teste da Razão de Verossimilhança) (Wilks, 2006), dado por:

$$
\Lambda=\frac{|E|}{|H+E|}
$$

em que E e H são as matrizes de somas de quadrados e de produtos residuais e de tratamentos, respectivamente.

Posteriormente, realizou-se ACP, para redução da dimensionalidade do conjunto original de variáveis com a menor perda de informação possível, agrupando os tratamentos similares mediante exames visuais em dispersões gráficas no espaço bi ou tridimensional.

$\mathrm{Na}$ análise de componentes principais, foram utilizadas as médias padronizadas das características de desempenho, características quantitativas da carcaça, e a matriz de correlações (R) entre as características, com base nos dados originais. A técnica de componentes principais consiste em transformar um conjunto de variáveis $\mathrm{X}_{1}, \mathrm{X}_{2}, \mathrm{X}_{3}, \ldots ., \mathrm{X}_{\mathrm{n}}$, que representa uma estrutura de interdependência, em um conjunto de variáveis $\mathrm{Y} 1, \mathrm{Y} 2, \ldots ., \mathrm{Y}_{\mathrm{n}}$, em que n é o número de variáveis. Os Yjs são funções lineares dos Xis, independentes entre si, e suas variâncias ordenadas para que seja possível comparar os grupos genéticos usando-se apenas aquelas que apresentam maior variância, ou seja, $\mathrm{Y}_{\mathrm{j}}$ é um componente principal, dado por: $\mathrm{Y}_{\mathrm{j}}$ (ou $\left.C P_{j}\right)=a_{i 1} X_{1}+a_{i 2} X_{2}+\ldots+a_{i n} X_{n}$.

Primeiramente, fez-se a ACP das 7 variáveis referentes ao desenvolvimento corporal e 17 variáveis relacionadas as características quantitativas da carcaça. Esses componentes foram construídos pela combinação da correlação $(\mathrm{P}<0,05)$ entre as variáveis, sendo extraídas em ordem decrescente de importância, em termos de sua contribuição para a variação total dos dados (Silva et al., 2010). O critério para classificação dos autovetores (valores que representam o peso de cada caractere, em cada componente, e variam de $-1 \mathrm{a}+1$ ) foi: valor absoluto $<0,30$, classificado como pouco significativo; 0,30-0,40, considerado mediamente significativo; e $\geq 0,50$, tido como altamente significativo (Coelho, 2003). As variáveis do desenvolvimento corporal e da carcaça que apresentaram autovetores com peso $\geq 0,50$ (altamente significativo) foram submetidas a nova ACP, para ranquear a variável com maior carga fatorial (escore), selecionado dentro do primeiro componente.

O propósito da terceira análise de componentes principais foi estudar a divergência entre os tratamentos por meio de um gráfico bidimensional. Portanto, foram calculados os escores relativos aos três tratamentos obtidos em relação aos dois primeiros componentes principais. Para o cálculo dos escores, utilizaram-se os autovalores associados aos dois primeiros componentes e a média da característica dentro dos tratamentos.

A importância relativa de um componente principal foi avaliada pela porcentagem da variância total, explicada pelo componente, como segue:

$$
\text { Importâncio de } C P_{j}=\frac{\lambda_{i}}{\Sigma \lambda_{i}} \times 100
$$

Onde: $\lambda$ i os autovalores de $\mathrm{R}$.

As análises foram realizadas por meio do $\mathrm{SAS}^{\circledR}$ (Statistical Analysis System, SAS Studio University Edition, version 3.5), utilizando-se os seguintes procedimentos: PROC GLM (análise multivariada); PROC PRINCOMP e PROC PRINQUAL (componentes principais).

\section{Resultados e Discussão}

$\mathrm{O}$ valor de $\mathrm{F}$ do teste de Wilks (Teste da Razão de Verossimilhança) foi significativo ( $\mathrm{P}=0,004)$, indicando que a hipótese de que os vetores dos efeitos de tratamento eram nulos é falsa, sinalizando que há discriminação entre tratamentos. 
Na Tabela 2 são apresentados os pesos médios das vacas dentro de cada tratamento, com o objetivo de demonstrar o comportamento dos animais durante a gestação. Pode-se observar que as vacas dos tratamentos G10 e P20 apresentavam ao final do período reprodutivo (PFM) pesos semelhantes, 449,17 e 450,17 kg, respectivamente. Já o tratamento P10, apresentava uma diferença de cerca de $17 \mathrm{~kg}$ em relação aos demais tratamentos. Na ocasião do parto houve uma maior discrepância dos pesos entre os animais, o tratamento G10 ganhou 17,83 kg (GMD de 0,083 kg dia-1) durante a gestação, parindo com peso médio de 467,00 kg. O tratamento P10 perdeu 23,31 kg (GMD de -0,095 kg dia-1) durante a gestação o que resultou em um peso ao parto de 454,06 kg. Já o tratamento P20, por sua vez, foi o que demonstrou maior perda de peso na gestação, $60,22 \mathrm{~kg}$ (GMD de -0,212 $\mathrm{kg} \mathrm{dia}^{-1}$ ) o que ocasionou um peso ao parto de 389,94 kg. A discrepância numérica no desempenho das vacas visualizado durante a gestação era esperada, uma vez que os animais foram classificados justamente em função da variação de peso durante a gestação para formação dos tratamentos.

Tabela 2. Análise estatística descritiva do peso ao final da reprodução (PFM, kg), ao parto (PP, kg), variação de peso (VARPV, $\mathrm{kg}$ ) e ganho médio diário de peso (GMD, $\mathrm{kg} \mathrm{dia}^{-1}$ ) de vacas de corte durante a gestação.

\begin{tabular}{lccc}
\hline \multirow{2}{*}{ Variável } & \multicolumn{3}{c}{ Tratamentos } \\
\cline { 2 - 4 } & G10 & P10 & P20 \\
\hline PFM & 449,17 & 477,38 & 450,17 \\
PP & 467,00 & 454,06 & 389,94 \\
VARPV & 17,83 & $-23,31$ & $-60,22$ \\
GMD & 0,083 & $-0,095$ & $-0,212$ \\
\hline
\end{tabular}

Fonte: Arquivo de dados do Laboratório de Bovinocultura de Corte da UFSM.

A variação de peso da vaca verificada entre os tratamentos pode ter impactado na partição de nutrientes entre a vaca e o feto durante a gestação. A partição de nutrientes durante a gestação é realizada através de uma regulação endócrina com base nos conceitos de homeorrese e homeostase (Bauman e Currie, 1980). Ainda de acordo com os autores, o conceito de homeostase é definido como a manutenção do equilíbrio fisiológico. Já homeorrese são mudanças orquestradas para as prioridades de um estado fisiológico, ou seja, coordenação do metabolismo em vários tecidos para suportar um estado fisiológico, como no caso da gestação. 
Figura 1. Precipitação total e insolação total ocorridas no período de parição para a cidade de Santa Maria - RS e médias históricas (1982-2012) (A). Distribuição dos partos dentro da época de parição de vacas de corte com diferentes variações de peso durante a gestação (B).

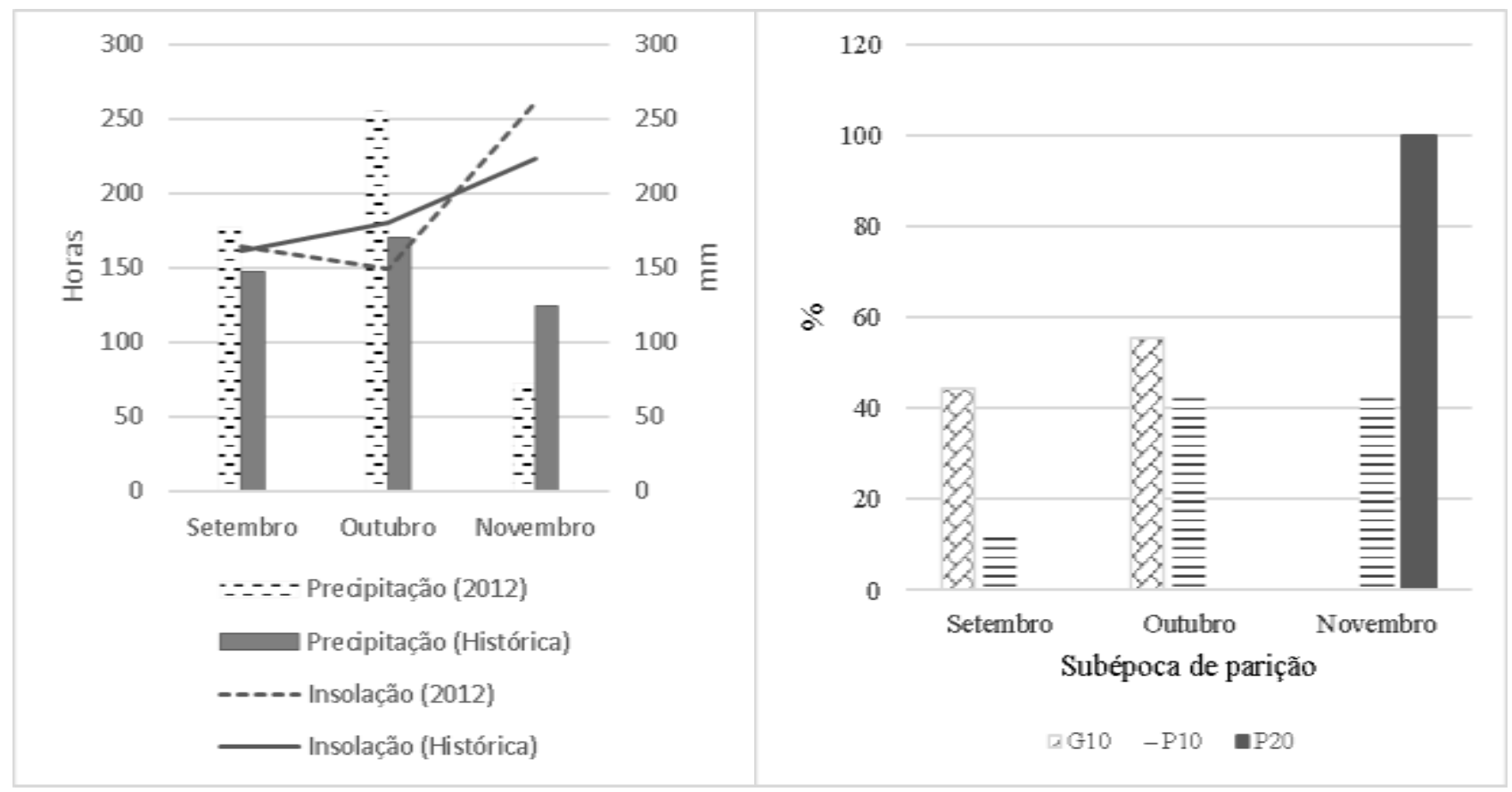

Fonte: Instituto Nacional de Meteorologia, Estação de Santa Maria, RS, Brasil (2018).

A variação de peso observada entre os tratamentos está relacionada com a concentração de partos visualizada entre os tratamentos e as condições climáticas (Figura 1). O tratamento G10 concentrou os partos nas duas primeiras subépocas de parição (setembro e outubro), meses que ocorreram precipitação acima da média. Em contraste o tratamento que perdeu mais peso, P20, concentrou a parição no último terço da estação (novembro), onde foi verificado uma redução na ordem de $41,3 \%$ no volume de chuvas para o referido período, causando queda na qualidade da forragem.

Em animais que estão com baixa condição corporal ou em carências nutricionais, o que acarreta em última análise em perda de peso, a partição de nutrientes pode ser afetada. Segundo McNeill et al. (1998) vacas com baixa condição corporal no final da gestação apresentaram consumo mais elevado de matéria seca do que matrizes com melhor condição corporal, porém a destinação dos nutrientes extras foi para os tecidos maternos e não para o feto. O que pode ser visualizado no tratamento P20, em que a perda de peso da matriz durante a gestação foi de tal forma impactante a ponto de prejudicar o desenvolvimento fetal. E reafirmado por Bell e Ehrhadt (2000) trabalhando com ovelhas alimentadas com 60\% dos requisitos de energia, mantiveram as taxas absolutas de absorção uterina de glicose apesar de uma redução de $25 \%$ na taxa de entrada de glicose materna. Onde o maior impacto foi verificado na perda materna de peso e condição corporal. Em contraste, a desnutrição mais grave de 30 a $40 \%$ de necessidade de energia causou uma diminuição acentuada da absorção uterina de glicose.

Já no tratamento P10, apesar da perda de peso durante a gestação, as vacas apresentavam maior peso no final do período reprodutivo, o que pode ter resultado em uma maior resiliência na partição de nutrientes entre vaca e feto durante a gestação, devido a uma maior capacidade de mobilização de reservas corporais dos animais do referido tratamento afim de manter o controle homeorréico, o que pode estar relacionado a mobilização tanto de aminoácidos do tecido muscular (perda de peso) quanto da lipólise do tecido adiposo da vaca para o suprimento de glicose para manter o adequado suprimento de metabólitos ao feto. No tratamento G10, no qual houve ganho de peso, não apresentou problemas com relação a partição de 
nutrientes. A demanda nutricional de manutenção tanto da vaca quanto da gestação foi suprida na sua totalidade, uma vez que houve ganho de peso.

As variáveis que representam o desenvolvimento e as características de carcaça da progênie (Tabela 3) foram agrupadas em dois fatores, o modelo foi capaz de explicar $100 \%$ das variâncias. O primeiro componente explicou $97,89 \%$ da variabilidade das características, e o segundo componente explicou 2,11\%. No primeiro componente ficaram situadas as variáveis com as maiores correlações significativas, sendo elas: PCQ, PCF, MARM, MUSC, OSSO e TRAS sendo consideradas as variáveis mais importantes na variação dos tratamentos estudados.

As variáveis que foram retiradas da análise por apresentarem baixa correlação ou a mesma não tenha sido significativas em nenhum dos componentes principais, sendo as mesmas: PNAS, PAJDESM, PAJ365, PAJ420, PAJ540, GMD, RCQ, RCF, AOL, GORD, ICC, DIAN, COST, CON, MAT e EGS. Pode-se observar que as variáveis de desempenho foram retiradas da segunda análise de ACP, o que indica que a variação de peso da vaca durante a gestação apresenta pouca influência no desenvolvimento de fêmeas.

No mesmo sentido do observado no presente estudo, Mullinikis et al. (2012) ao estudarem diferentes estratégias de alimentação para vacas prenhas, não observaram efeito significativo no desempenho da progênie como peso ao desmame, peso ao início e ao final da fase de terminação e no ganho de peso ao comparar os tratamentos nos quais as vacas perderam peso na gestação (-14 kg) com vacas que ganharam peso na gestação (6 ou $2 \mathrm{~kg}$ de peso vivo). Long et al. (2010) ao avaliarem o efeito da restrição alimentar da vaca prenha não observaram diferenças significativas no peso ao nascimento, peso ao desmame, peso de abate e ganho de peso da progênie de vacas que perderam $(-62 \mathrm{~kg})$ ou ganharam peso $(+42 \mathrm{~kg})$ durante a gestação. 
Tabela 3. Análise de componentes principais das variáveis da carcaça da progênie de vacas com diferentes variações de peso durante a gestação.

\begin{tabular}{|c|c|c|}
\hline \multirow{2}{*}{ Componentes da variância } & \multicolumn{2}{|c|}{ Componentes principais } \\
\hline & 1 & 2 \\
\hline Autovalor & 3582,83 & 77,32 \\
\hline Proporção (\%) & 97,89 & 2,11 \\
\hline Proporção acumulada (\%) & 97,89 & 100,00 \\
\hline Variáveis & \multicolumn{2}{|c|}{ Correlações com os componentes principais } \\
\hline PAJDESM & 0,96 & 0,28 \\
\hline PNAS & 0,26 & 0,97 \\
\hline PAJ 210 & 0,99 & 0,14 \\
\hline PAJ365 & 0,95 & $-0,32$ \\
\hline PAJ420 & 0,99 & 0,14 \\
\hline PAJ540 & 0,99 & $-0,12$ \\
\hline GMD & $-0,41$ & $-0,91$ \\
\hline PCQ & $1,00 *$ & 0,02 \\
\hline PCF & $1,00 *$ & 0,02 \\
\hline RCQ & 0,91 & 0,41 \\
\hline $\mathrm{RCF}$ & 0,93 & 0,37 \\
\hline AOL & 0,61 & 0,79 \\
\hline MARM & $1,00^{*}$ & 0,03 \\
\hline MUSC & $1,00^{*}$ & 0,01 \\
\hline GORD & 1,00 & 0,08 \\
\hline ICC & 0,99 & 0,10 \\
\hline OSSO & $1,00^{*}$ & $-0,07$ \\
\hline TRAS & $1,00^{*}$ & 0,03 \\
\hline DIAN & 1,00 & 0,10 \\
\hline COST & 0,97 & $-0,24$ \\
\hline $\mathrm{COM}$ & 0,94 & $-0,34$ \\
\hline MAT & $-0,99$ & $-0,16$ \\
\hline EGS & 0,99 & 0,12 \\
\hline
\end{tabular}

*valor para correlação de Pearson, $\mathrm{P}<0,05$

Fonte: Arquivo de dados do Laboratório de Bovinocultura de Corte da UFSM

Alinhado com o presente estudo, a ausência de efeito da nutrição materna na AOL, EGS e RCQ da progênie é relatado por diversos autores na literatura como Mohrhauser et al. (2015), Long et al. (2010), Underwood et al. (2010) e Larson et al. (2009). Cabe ressaltar que praticamente todos os trabalhos citados no presente estudo abordaram o efeito da programação fetal nas características carcaça de novilhos, nesse sentido o presente estudo é inovador e aborda um tema ainda pouco explorado na literatura. Normalmente as fêmeas produzidas em sistemas de cria são destinadas a reposição das matrizes, porém em sistemas que atingem elevados índices de natalidade, há um excedente de fêmeas produzidas e essas passam a ser destinadas para terminação e um importante ativo do sistema produtivo.

Após a realização da primeira ACP, das 23 variáveis inicialmente estudadas, 6 foram selecionadas para uma segunda análise. Sendo as mesmas: PCQ, PCF, MUSC, OSSO, TRAS, MARM. Na Tabela 4 são apresentados escores das variáveis com os componentes principais obtidos na segunda análise. Pode-se visualizar que o primeiro componente principal, assim como na análise anterior, explica a maior proporção da variância dos dados 99,00\%. O PCF apresentou a maior correlação com o primeiro componente principal, sendo considerada a variável mais importante na variação dos tratamentos estudados, embora 
as demais variáveis também tenham apresentados elevadas correlações com o primeiro componente principal e possam ser consideradas de elevada influência na discriminação dos tratamentos.

Tabela 4. Análise de componentes principais das variáveis da carcaça da progênie de vacas com diferentes variações de peso durante a gestação.

\begin{tabular}{lcc}
\hline \multirow{2}{*}{ Componentes de variância } & \multicolumn{2}{c}{ Componentes principais } \\
\cline { 2 - 3 } & 1 & 2 \\
\hline Autovalor & 1140,43 & 0,08 \\
Proporção (\%) & 99,00 & 0,11 \\
Proporção acumulada (\%) & 99,00 & 100,00 \\
\hline Variáveis & Correlações com os componentes principais \\
\hline PCQ & $0,999 *$ & $-0,003$ \\
PCF & $1,009^{*}$ & $-0,001$ \\
MARM & $0,999 *$ & $-0,008$ \\
MUSC & $0,999 *$ & 0,011 \\
OSSO & $0,996 *$ & 0,086 \\
TRAS & $0,999 *$ & $-0,009$ \\
\hline
\end{tabular}

* valor para correlação de Pearson, $\mathrm{P}<0,05$

Fonte: Arquivo de dados do Laboratório de Bovinocultura de Corte da UFSM

Na Figura 2 é representada graficamente a dispersão das variáveis obtidas através da segunda ACP. Pode-se observar que os tratamentos estudados demonstraram elevada dispersão gráfica, indicando que há diferença entre os grupos estudados. É possível visualizar que as variáveis se concentraram ao longo do eixo que representa o primeiro componente principal, o que é fruto da alta proporção da variância total dos dados explicada pelo referido componente principal (98,93\%).

No quadrante I está disposto o tratamento G10, o mesmo apresentou maiores valores para PCQ, PCF, TRAS, MUSC e MARM do que os tratamentos P10 e P20. O que vai de encontro com o relatado na literatura, onde o maior impacto da nutrição materna durante a gestação se dá em prejuízo na miogênese e adipogênese. Segundo Du et al. (2010) a restrição nutricional da vaca durante a gestação reduz a miogênese, diminui o número de fibras musculares e a massa muscular da progênie. Nesse sentido Underwood et al. (2010) relatam maior PCQ em filhos de vacas mantidas em pastagem melhorada (348,20 kg) do que filhos de vacas mantidas em pastagem nativa $(329,50 \mathrm{~kg})$.

Já o tratamento P20 ficou localizado no quadrante II, resultando em menores valores de PCQ, PCF, TRAS, MUSC e MARM, o que vai de encontro ao exposto na literatura sobre o impacto nutrição materna na programação fetal da progênie. Pode-se observar que o tratamento P10 apresentou maior quantidade absoluta de osso, ambos localizados no quadrante IV.

O maior PCQ, PCF, TRAS, MUSC obtidos no tratamento G10 pode ser atribuído a maior hiperplasia das fibras musculares no período de gestação. O crescimento do músculo esquelético envolve aumentos no número de células (hiperplasia) e no tamanho das células (hipertrofia). Segundo Karunaratne et al. (2005) após o nascimento não há a formação de novas fibras musculares e sim o aumento no tamanho das fibras pré-estabelecidas durante a gestação, o que é reafirmado por Buttery et al. (2000). Regnault et al. (2005) citam que o suprimento inadequado tanto de oxigênio, quanto de aminoácidos para o feto podem comprometer ou impedir o crescimento natural das proteínas fetais. Funston et al. (2010) afirmam que o suprimento de aminoácidos tem efeito sobre o controle da multiplicação do RNA e na síntese de proteína.

Através da análise dos resultados obtidos, pode-se afirmar que o ganho de peso durante a gestação aumentou o número potencial das células musculares, refletindo em maiores valores para as variáveis que representam a expressão 
muscular da carcaça dos animais como o PCQ, PCF, TRAS e MUSC. O maior PCQ visualizado para o tratamento G10 resultou em maior peso de PCF, TRAS e MUSC do que os demais tratamentos. O que pode ser visualizado através da alta correlação (Quadro 1) entre o PCQ com o PCF $\left(\mathrm{r}^{2}=0,99 ; \mathrm{P}<0,0001\right)$, TRAS $\left(\mathrm{r}^{2}=0,95 ; \mathrm{P}<0,0001\right)$ e MUSC $\left(\mathrm{r}^{2}=0,94 ; \mathrm{P}<0,0001\right)$.

Figura 2. Gráfico bidimensional dos componentes principais em função do efeito das classes de variação de peso da matriz durante a gestação no desenvolvimento e nas características de carcaça da progênie.

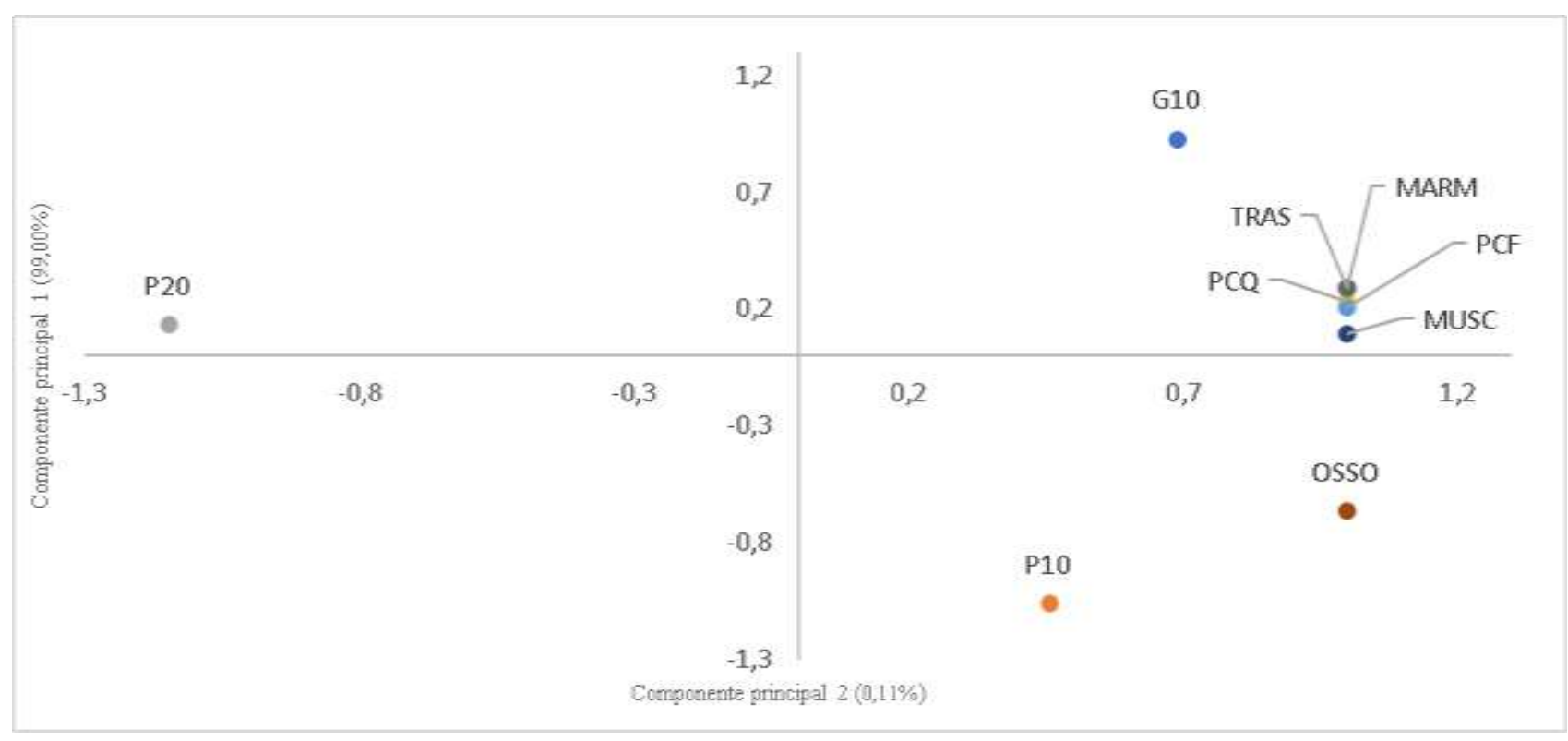

Fonte: Arquivo de dados do Laboratório de Bovinocultura de Corte da UFSM

Segundo Du et al. (2010) o estágio fetal é o mais eficiente para aumentar o marmoreio da carne de bovinos. Um adequado plano nutricional nessa fase, aumenta o número de células mesenquimais comprometidas com a adipogênese, aumentando o número de adipócitos intramusculares. Underwood et al. (2008) ao estudarem o fornecimento de pastagem nativa ou melhorada para vacas dos 120 aos 210 dias de gestação relatam um aumento no teor de gordura do músculo Longissimus dorsi nos novilhos nascidos de vacas que se alimentaram de pastagem nativa melhorada. Larson et al. (2009) relatam aumento no grau de MARM da progênie de vacas que receberam suplementação proteica em relação a que não receberam, o mesmo é afirmado por Tong et al. (2008). 
Quadro 1. Correlações de Pearson das variáveis utilizadas na segunda análise de componentes principais.

\begin{tabular}{|c|c|c|c|c|c|c|}
\hline & PCQ & PCF & MARM & MUSC & OSSO & TRAS \\
\hline PCQ & - & $0,99^{1}$ & $-0,34$ & 0,94 & 0,83 & 0,95 \\
\hline PCF & $<0,0001^{2}$ & - & $-0,34$ & 0,94 & 0,83 & 0,95 \\
\hline MARM & 0,0433 & 0,0418 & - & $-0,23$ & $-0,22$ & $-0,27$ \\
\hline MUSC & $<0,0001$ & $<0,0001$ & 0,1669 & - & 0,73 & 0,91 \\
\hline OSSO & $<0,0001$ & $<0,0001$ & 0,1856 & $<0,0001$ & - & 0,77 \\
\hline TRAS & $<0,0001$ & $<0,0001$ & 0,1135 & $<0,0001$ & $<0,0001$ & - \\
\hline
\end{tabular}

${ }^{1}$ Diagonal superior representa os valores da correlação de Pearson entre as variáveis;

${ }^{2}$ Diagonal inferior representa o valor de $\mathrm{P}$ para as correlações.

Fonte: Arquivo de dados do Laboratório de Bovinocultura de Corte da UFSM

Normalmente os rebanhos de cria são mantidos em sistemas extensivos em áreas de solos de menor fertilidade e, na maioria das vezes, com alta carga animal, incompatível com capacidade de suporte (Pellegrini e Lopes, 2011), tendo como base alimentar forrageiras que estão sujeitas a oscilações no valor nutritivo e na produção de forragem (Silveira et al., 2014), seja pela ocorrência sazonal das chuvas ou por temperaturas baixas em determinadas épocas do ano, que muitas vezes coincidem com o período gestacional das vacas. Porém o baixo plano nutricional da vaca prenha, o que em última instância irá impactar sobre a variação de peso da vaca, que é o foco do presente estudo, impacta diretamente sobre a resposta que a progênie irá ter na terminação e no retorno financeiro da atividade. Do ponto de vista econômico os resultados obtidos são impactantes tanto para o produtor quanto para o consumidor, uma vez que um baixo desenvolvimento pré-natal gerou carcaças mais leves, o que reduz a remuneração obtida por cabeça comercializada e carne com menor grau de marmoreio o que pode resultar em carne com menor suculência e palatabilidade.

\section{Conclusão}

O ganho de peso da vaca durante a gestação influencia a programação fetal da progênie, resultando em maiores pesos de carcaça quente e fria, traseiro, músculo e marmoreio.

A maior taxa de perda de peso da vaca durante a gestação, entre 10 e $20 \%$ do peso vivo, impacta negativamente nas características de carcaça da progênie, resultando em menores pesos de carcaça quente de quente, fria, traseiro, músculo, osso e marmoreio.

A perda de peso da vaca durante a gestação entre 0 a $10 \%$ do peso vivo resultou em maior quantidade de osso na carcaça de novilhas abatidas aos 18 meses de idade.

O crescimento e desenvolvimento de novilhas não é influenciado pela variação de peso da vaca durante a gestação.

\section{Referências}

Alvares, C. A., Stape, J. L., Sentelhas, P. C., De Moraes, G., Leonardo, J., \& Sparovek, G.(2013). Köppen's climate classification map for Brazil. Meteorologische Zeitschrift, 22(6), 711-728.

Anualpec (2016). Anuário da pecuária brasileira. Agra FNP pesquisas Ltda. 380 pp.

Bauman, D. E. \& Currie, W. B. (1980). Partitioning of Nutrients During Pregnancy and Lactation: A Review of Mechanisms Involving Homeostasis and Homeorhesis. Journal of Dairy Science, Madison, 63, 1514-1529.

Bell, A. W. \& Ehrhardt, R. A. (2000). Regulation of Macronutrient Partitioning between Maternal and Conceptus Tissues in the Pregnant Ruminant. In: CRONJE, P. Ruminant physiology: digestion, metabolism, growth, and reproduction. CAB International, 474p.

Buttery, P. J., Brameld, J. M., \& Dawson, J. M. (2000) Control and Manipulation of Hyperplasia and Hypertrophy in Muscle Tissue. In: CRONJE, P. Ruminant physiology: digestion, metabolism, growth, and reproduction. CAB International, 474p.

Coelho, A. M. (2003) Agricultura de precisão: manejo da variabilidade espacial e temporal dos solos e das culturas. In: Curi, N., Marques, J. J., Guilherme, L. R. G., Lima, J. M. De, Lopes, A. S., Alvares, V. H. (Ed.). Tópicos em ciência do solo. Viçosa: Sociedade Brasileira de Ciência do Solo, 3 , $259-290$. 
Du, M., Tong, J., Zhao, J., Underwood, K. R., Zhu, M., Ford, S. P., \& Nathanielsz, P. W. (2010). Fetal programming of skeletal muscle development in ruminant animals. Journal of Animal Science, 88 , E51-E60.

Ferreira, M. C. N., Miranda, R., Figueiredo, M. A., Costa, O. M., \& Palhano, H. B. (2013). Impact of body condition on pregnancy rate of cows nellore under pasture in fixed time artificial insemination (TAI) program. Semina: Ciências Agrárias, 34, 1861-1868.

Funston, R. N., Larson, D. M., \& Vonnahme, K. A. (2010). Effects of maternal nutrition on conceptus growth and offspring performance: Implications for beef cattle production. Journal of Animal Science, 88, E205-E215.

Greenwood, P. L. \& Cafe, L. M. (2007). Prenatal and pre-weaning growth and nutrition of cattle: Long-term consequences for beef production. Animal, 1(9), $1283-1296$

Greenwood, P. L., Bell, A. W., Vercoe, P. E., \& Viljoen, G. J. (2010). Managing the Prenatal Environment to Enhance Livestock Productivity. Springer: EUA, 302p

Karunaratne, J. F., Ashton, C. J. \& Stickland, N. C. (2005). Fetal programming of fat and collagen in porcine skeletal muscles. Journal of Anatomy, 207, 763768.

Larson, D. M., Martin, J. L., Adams, D. C., \& Funston, R. N. (2009). Winter grazing system and supplementation during late gestation influence performance of beef cows and steer progeny. Journal of Animal Science, 87(3), 1147-1155.

Leão, J. P., Neiva, J. N. M., Restle, J., Míssio, R. L., Paulino, P. V. R., Miotto, F. R. C., Santana, A. E. M., Sousa, L. F., \& Alexandrino, E. (2013). Carcass and meat characteristics of different cattle categories fed diets containing crude glycerin. Semina: Ciências Agrárias, 34(1), 431-444.

Long, N. M., Prado-Cooper, M. J., Krehbiel, C. R., Desilva, U. E., \& Wettemann, R. P. (2010). Effects of nutrient restriction of bovine dams during early gestation on postnatal growth, carcass and organ characteristics, and gene expression in adipose tissue and muscle. Journal of Animal Science, 88(10), 32513261.

Nabinger, C., Ferreira, E. T., Freitas, A. K., Carvalho, P. C. F., 7 Sant'anna, D. M. (2009). Produção animal com base no campo nativo: aplicações de resultados de pesquisa. In: PILLAR, V.P. et al. Campos Sulinos - conservação e uso sustentável da biodiversidade, Brasília: MMA, 403 p.

Mcneill, D. M., Kelly, R. W. \& Williams, I. H. (1998). Partition of nutrients in moderately fat ewes compared with lean ewes given ad libitum access to feed in late pregnancy. Australian Journal of Agricultural Research, 49, 575-580.

Mohrhauser, D. A., Taylor, A. R., Underwood, K. R., Pritchard, R. H., Wertz-Lutz, A. E., Blair, \& A. D. (2015). The influence of maternal energy status during midgestation on beef offspring carcass characteristics and meat quality. Journal of Animal Science, 93(2), 786-793.

Mulliniks, J. T., Sawyer, J. E., Mathis, C. P., Cox, S. H., \& Petersen, M. K. (2012). Winter protein management during late gestation alters range cow and steer progeny performance. Journal of animal science, 90(13), 5099-5106.

Pellegrini, C. B. \& Lopes, L. F. D. (2011). Comportamento reprodutivo de vacas de corte manejadas em pastagem natural com duas cargas animais e duas idades à desmama. Revista Brasileira de Zootecnia, 40(11), 2606-2612.

Pereira, C. H., Patino, H. O., Hoshide, A. K., Abreu, D. C., Rotz, C. A., \& Nabinger, C. (2018). Grazing supplementation and crop diversification benefits for southern Brazil beef: A case study. Agricultural Systems, 62, 1-9.

Regnault, T. R. H., Friedman, J. E., Wilkening, R. B., Anthony, R. V., \& Hay, W. W. (2005). Fetoplacental transport and utilization of amino acids in IUGRa review. Placenta, 26, S52-S62.

Rezende, P. L. P., Restle, J., Fernandes, J. J. R., Freitas Neto, M. D., Prado, C. S., \& Pereira, M. L. R. (2012). Carcass and meat characteristics of crossbred steers submitted to different nutritional strategies at growing and finishing phases. Ciência Rural, 42(5), 875-881.

Silva, S. A., Lima, J. S. De S., Xavier, A. C., \& Teixeira, M. M. (2010). Variabilidade espacial de atributos químicos de um Latossolo Vermelho-Amarelo húmico cultivado com café. Revista Brasileira de Ciência do Solo, 34, 15-22.

Silveira, M. F. D., Restle, J., Alves Filho, D. C., Missio, R. L., Donicht, P. A. M. M., Segabinazzi, L. R., \& Joner, G. (2014). Suplementação com gordura protegida para vacas de corte desmamadas precocemente mantidas em pastagem natural. Arquivo Brasileiro de Medicina Veterinaria e Zootecnia, 66(3), 809817.

Streck, E. V., Kämpf, N., Dalmolin, R. S. D., Klamt, E., Nascimento, P. D., Schneider, P., 7 Pinto, L. F. S. (2008). Solos do Rio Grande do Sul. Porto Alegre: UFRGS, Departamento de Solos, Faculdade de Agronomia, 222 p.

Tong, J., Zhu, M. J., Underwood, K. R., Hess, B. W., Ford, S. P., \& Du, M. (2008). AMP-activated protein kinase and adipogenesis in sheep fetal skeletal muscle and 3T3-L1 cells. Journal of Animal Science, 86, 1296-1305.

Underwood, K. R., Kimzey, J. M., Tong, J., Price, P. L., Grings, E. E., \& Hess, B. W. (2008). Gestational nutrition affects growth and adipose tissue deposition in steers. In: proceeding western section, american society of animal science. Proceedings... p. 29-32.

Underwood, K. R., Tong, J. F., Price, P. L., Roberts, A. J., Grings, E. E., Hess, B. W., \& Du, M. (2010). Nutrition during mid to late gestation affects growth, adipose tissue deposition, and tenderness in cross-bred beef steers. Meat science, 86(3), 588-593.

Vaz, F. N., Restle, J., Arboite, M. Z., Pascoal, L. L., Alves Filho, D. C., \& Pacheco, R. F. (2010). Características de carcaça e da carne de novilhos e novilhas superjovens, terminados com suplementação em pastagem cultivada. Ciência Animal Brasileira, 11(1), 42-52.

Wilks, D. S. (2006). Statistical Methods in the Atmospheric Sciences. (2a ed.), California: Elsevier Science \& Technology Books Academic Press, 704 p. 